\title{
Correction to: Insights on dispersal and recruitment paradigms: sex- and age-dependent variations in a nomadic breeder
}

\author{
Paul Acker ${ }^{1,2}$ (C) Charlotte Francesiaz ${ }^{2} \cdot$ Arnaud Béchet $^{3} \cdot$ Nicolas Sadoul $^{4} \cdot$ Catherine M. Lessells $^{5} \cdot$ Agata S. Pijl $^{5}$. \\ Aurélien Besnard ${ }^{2}$
}

Published online: 1 December 2017

(c) Springer-Verlag GmbH Germany, part of Springer Nature 2017

\section{Correction to: Oecologia \\ https://doi.org/10.1007/s00442-017-3972-7}

Unfortunately, Table 1 was incorrectly published in the original article and the same is corrected by this Erratum. The original article was corrected.

The original article can be found online at https://doi. org/10.1007/s00442-017-3972-7.

Paul Acker

paul.acker@noos.fr

1 Laboratoire Évolution et Diversité Biologique (EDB) UMR 5174, Université Paul Sabatier, CNRS, ENSFEA, IRD, 118

Route de Narbonne, 31062 Toulouse, France

2 CEFE UMR 5175, CNRS, PSL Research University, EPHE UM, SupAgro, IRD INRA, 1919 Route de Mende, 34293 Montpellier, France

3 Centre de Recherche de la Tour du Valat, Le Sambuc, 13200 Arles, France

4 Les Amis des Marais du Vigueirat, Marais du Vigueirat, Mas Thibert, 13104 Arles, France

5 Department of Animal Ecology, Netherlands Institute of Ecology (NIOO-KNAW), Postbus 50, $67000 \mathrm{AB}$ Wageningen, The Netherlands 


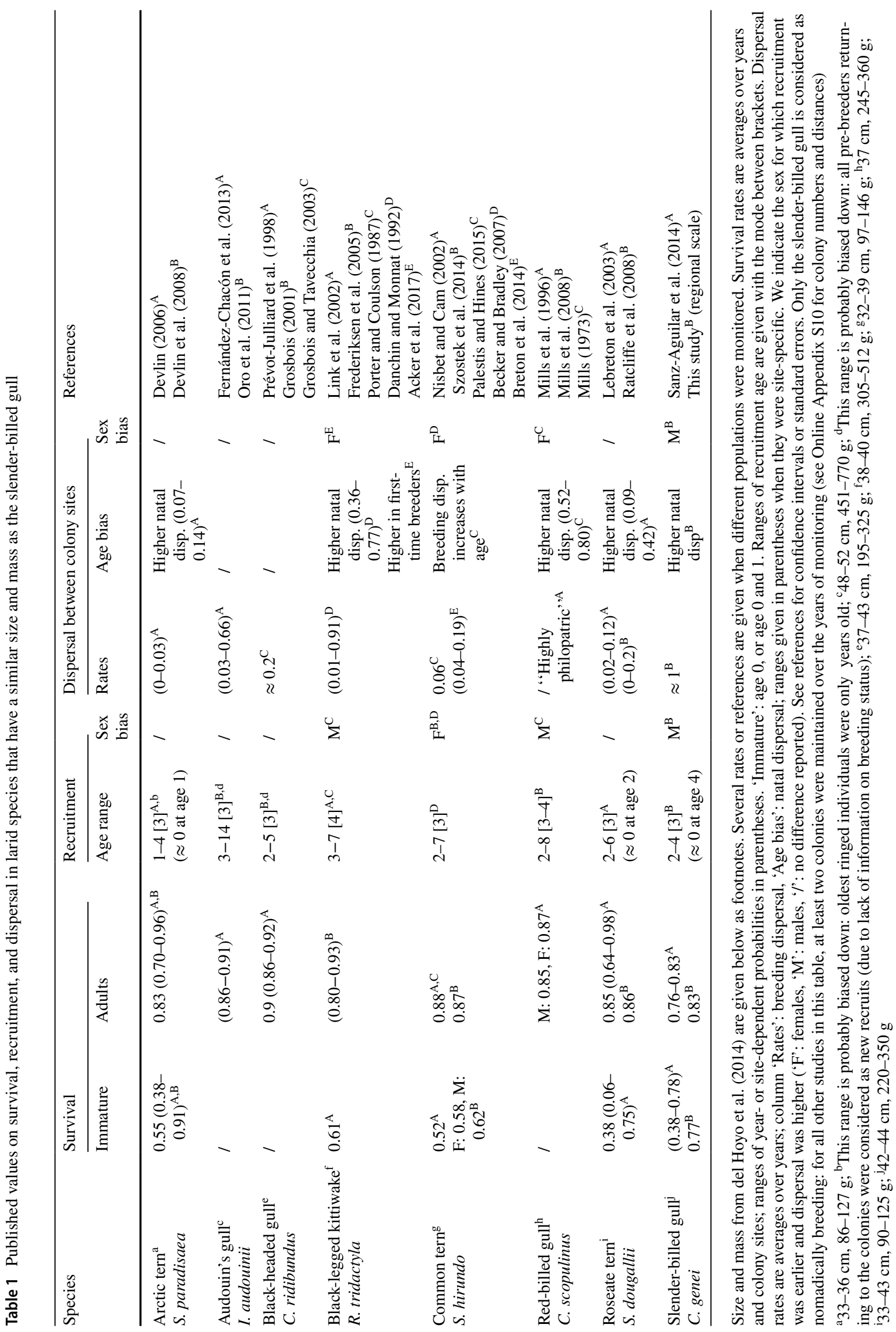

